\title{
S25-05
}

\section{SUBJECTIVE COGNITIVE IMPAIRMENT: FUNCTIONAL MRI DURING DIVIDED ATTENTION AND MEASUREMENT OF AMYLOID LOAD USING ${ }^{11}$ C-PIB PET}

J. Rodda ${ }^{1}$, T. Dannhauser ${ }^{1,2}$, D. Cutinha ${ }^{1,2}$, A. Okello ${ }^{3}$, S. Shergill ${ }^{4}$, D. Brooks ${ }^{3}$, Z. Walker ${ }^{1,2}$

${ }^{1}$ Mental Health Sciences, University College London, London, ${ }^{2}$ North Essex Partnership NHS Foundation Trust, Essex, ${ }^{3}$ Imperial College London, ${ }^{4}$ Institute of Psychiatry at the Maudsley, London, UK

Background: Evidence suggests that healthy older adults with subjective memory complaints are at increased risk of dementia Subjective Cognitive Impairment ( $\mathrm{SCl}$ ) may precede Mild Cognitive Impairment $(\mathrm{MCl})$ in the clinical continuum of Alzheimer's disease (AD). Attentional deficits may be present early in $A D$, and associated functional changes have been reported in both $\mathrm{MCl}$ and $A D$. In the present study, activation during divided attention in $\mathrm{SCl}$ subjects was investigated using functional magnetic resonance imaging (fMRI). Additionally, amyloid uptake was investigated using ${ }^{11} \mathrm{C}-\mathrm{PIB}$ with positron emission tomography (PET).

Methods: Brain activation in $11 \mathrm{SCl}$ subjects and 10 controls was compared during a divided attention task using fMRI. Additionally, five $\mathrm{SCl}$ subjects and 14 cognitively normal healthy controls underwent ${ }^{11} \mathrm{C}-\mathrm{PIB}$ PET scanning. Criteria for diagnosis of SCI were:

1. self-reported memory complaints,

2. objectively normal cognition on detailed neurocognitive testing,

3. absence of psychiatric or causative physical illness,

4. normal activities of daily living and

5. absence of $\mathrm{MCl}$ or dementia.

Results: There were no differences in performance between $\mathrm{SCl}$ and control groups in terms of cognitive or behavioural measures. However, SCls had increased activation in left medial temporal lobe, and bilateral thalamus, posterior cingulate and caudate. One $\mathrm{SCl}$ subject and one control subject had a pattern of ${ }^{11} \mathrm{C}$-PIB uptake similar to that seen in AD.

Conclusions: The activation changes identified in $\mathrm{SCl}$ may relate to compensatory increased activation in the face of early $\mathrm{AD}$ pathology. Larger, longitudinal studies are needed to determine the extent and significance of PIB uptake in SCI. 